\title{
EXPERIMENTAL OFF-PUMP CORONARY ARTERY REVASCULARIZATION WITH ADENOSINE-ENHANCED REPERFUSION
}

Satoshi Muraki, MD

Cullen D. Morris, MD

Jason M. Budde, MD

Daniel A. Velez, MD

Zhi-Qing Zhao, MD

Robert A. Guyton, MD

Jakob Vinten-Johansen, PhD
Objective: Although beating heart coronary artery bypass grafting has recently gained popularity, it eliminates the protective strategies (ie, cardioplegia) developed for use in conventional cardiac operations. We recently introduced the technique of perfusion-assisted direct coronary artery bypass to perfuse the grafted vessels during multivessel off-pump coronary artery bypass grafting. In the present study we tested the hypothesis that intracoronary reperfusion with the cardioprotective agent adenosine during simulated perfusionassisted direct coronary artery bypass attenuates reperfusion injury.

Methods: In anesthetized dogs the heart was exposed, and the left anterior descending coronary artery was ligated for 75 minutes. Reperfusion was achieved through a catheter in the left anterior descending coronary artery by means of a computer-controlled pump. Intracoronary left anterior descending coronary artery perfusion pressure was continuously matched to mean arterial blood pressure. In one group (adenosine group) $10 \mu \mathrm{mol} / \mathrm{L}$ adenosine was added to the blood during the first 30 minutes of reperfusion, whereas another group (vehicle group) received a comparable volume of saline solution.

Results: During the first 30 minutes of reperfusion, blood flow through the left anterior descending coronary artery was significantly greater $(P<.05)$ in the adenosine group than in the vehicle group $(150.6 \pm 21.9$ vs $50.2 \pm$ $11.3 \mathrm{~mL} / \mathrm{min}$ at 15 minutes of reperfusion). Although there were no group differences in postischemic wall motion, infarct size was significantly smaller in the adenosine group than in the vehicle group $(11.1 \% \pm 3.0 \%$ vs $28.0 \% \pm 4.0 \%$ of area at risk, $P<.05)$. Myeloperoxidase activity in the necrotic tissue, an index of neutrophil accumulation, tended to be lower in the adenosine group than in the vehicle group $(58.6 \pm 14.2$ vs $91.0 \pm 21.6$ $\Delta$ AbsUnits $\cdot \min ^{-1} \cdot \mathrm{g}^{-1}$ tissue). In isolated postischemic left anterior descending coronary artery rings, the maximal relaxation response to the endothelium-dependent vasodilator acetylcholine was significantly greater in the adenosine group than in the vehicle group $(97.9 \% \pm 5.6 \%$ vs $64.7 \%$ $\pm 6.5 \%, P<.05)$.

Conclusion: This novel reperfusion strategy for off-pump coronary artery bypass grafting can be used not only in cases requiring multiple grafting but also to attenuate necrosis and endothelial dysfunction in acute evolving infarction. (J Thorac Cardiovasc Surg 2001;121:570-9)
From the Division of Cardiothoracic Surgery, Carlyle Fraser Heart Center, Emory University School of Medicine, Atlanta, Ga.

Supported by the Carlyle Fraser Heart Center of Crawford Long Hospital, Emory University, and a Scientific Development Award

(Z.-Q.Z.) and a Grant-in-Aid (J.V.-J.) from the National American Heart Association.

Copyright (C) 2001 by The American Association for Thoracic Surgery

0022-5223/2001 $\$ 35.00+0 \quad \mathbf{1 2 / 1 / 1 1 2 3 4 2}$

doi: $10.1067 / \mathrm{mtc} .2001 .112342$
0 ff-pump coronary artery bypass grafting (OPCABG) requires a period of coronary artery occlusion to accomplish a bloodless field. This obligate coronary occlusion may be superimposed on pre-existing ischemia of varying degrees, especially in acute evolving infarction in which blood flow is totally occluded. In addition, off-pump surgical techniques have limited the strategies to protect the heart from ischemia or reperfusion injury. Reperfusion has been 
postulated to produce lethal injury to cells that are still alive at the time of reperfusion, and therefore reperfusion injury limits its potential benefit on myocardial salvage. ${ }^{1,2}$ To avoid prolonged ischemia and possible reperfusion injury, we recently introduced perfusionassisted direct coronary artery bypass (PADCAB), ${ }^{3}$ a novel technique by which to perfuse the grafted vessels by using a computer-controlled blood delivery system during multivessel OPCABG. This technique allows rapid perfusion of grafted segments before completion of the proximal anastomosis.

Although many studies have identified effective cardioprotective agents to attenuate ischemia-reperfusion (I-R) injury, ${ }^{1,2}$ a clinically useful strategy to protect the ischemic myocardium has not been developed for OPCABG when extracorporeal circulation and cardioplegia are not options. Among the various cardioprotective drugs, adenosine has been extensively investigated both in clinical and experimental studies. ${ }^{4,5}$ Potent cardioprotective effects of adenosine on I-R injury are derived from reversal of microvascular vasoconstriction, inhibition of neutrophil functions, reduction of platelet aggregation, and replenishment of highenergy stores in endothelial and myocardial cells. 5,6 $\mathrm{A}_{1}$-receptor-, ${ }^{7} \mathrm{~A}_{2}$-receptor-, ${ }^{8}$ and possibly $\mathrm{A}_{3}$-receptor-mediated ${ }^{9}$ mechanisms are involved in adenosine cardioprotection.

Accordingly, the present study tested the hypothesis that the selective delivery of adenosine to a target vessel with a computer-controlled perfusion delivery pump system during simulated off-pump revascularization would attenuate reperfusion injury, reduce coronary artery endothelial dysfunction, and salvage myocardium.

\section{Methods}

Experimental preparation. All animals received humane care in compliance with the "Guide for the Care and Use of Laboratory Animals" prepared by the Institute of Laboratory Animal Resources, National Research Council, and published by the National Academy Press, revised 1996. A total of 18 healthy mongrel dogs were initially anesthetized with intravenous $2.5 \%$ thiopental $(20 \mathrm{mg} / \mathrm{kg})$, followed by an infusion of fentanyl citrate $\left(0.4 \mu \mathrm{g} \cdot \mathrm{kg}^{-1}\right.$. $\left.\mathrm{min}^{-1}\right)$ and diazepam $\left(0.003 \mathrm{mg} \cdot \mathrm{kg}^{-1} \cdot \mathrm{min}^{-1}\right)$ during the experiment. Each dog was endotracheally intubated and mechanically ventilated to maintain $\mathrm{PaO}_{2}$ greater than 100 $\mathrm{mm} \mathrm{Hg}, \mathrm{PaCO}_{2}$ of 35 to $45 \mathrm{~mm} \mathrm{Hg}$, and $\mathrm{pH}$ of 7.35 to 7.45 . Metabolic acidemia was corrected with sodium bicarbonate infusion as needed. Polyethylene catheters were inserted into the femoral artery bilaterally, with one side being used for monitoring systemic arterial pressure and microsphere reference sampling and the contralateral side being used as an arterial blood source for the coronary arterial perfusion circuit at the time of reperfusion (Fig 1, A).
The chest was opened by lateral thoracotomy at the fifth intercostal space, and the pericardium was incised and tented to cradle the heart. A Millar MPC-500 temperature-compensating solid-state catheter (Millar Instruments, Inc, Houston, Tex) was placed in the left ventricular cavity through an apical stab wound to measure instantaneous left ventricular pressure. A polyethylene catheter was inserted into the left atrium for injection of colored microspheres. A proximal portion of the left anterior descending (LAD) coronary artery was dissected and loosely encircled with a 2-0 silk suture for subsequent LAD artery occlusion.

A pair of 5-MHz piezoelectric ultrasonic crystals 2.5 to 3.0 $\mathrm{mm}$ in diameter was placed in the subendocardium of the myocardium perfused by the LAD (ischemic-reperfused segment) to measure instantaneous segmental dimensions by means of a sonomicrometer (model 120; Triton Technology, San Diego, Calif). A model SPC-320 2F solid-state pressure transducer (Millar Instruments) was inserted into a small right ventricular branch of the LAD artery distal to the site of ligation to measure instantaneous LAD intracoronary pressure (Fig 1, A). The position of the transducer catheter did not interfere with LAD blood flow. The dogs were systemically heparinized with an initial 300-U/kg dose of heparin sodium supplemented with $300 \mathrm{U} / \mathrm{kg}$ every 90 minutes.

Experimental protocol. The protocol is schematically presented in Fig 1, B. Hemodynamic and segmental function data were obtained, and colored microspheres were injected at baseline. Each dog then received a bolus injection of lidocaine (1.2 $\left.\mathrm{mg} \cdot \mathrm{kg}^{-1}\right)$ followed by continuous infusion $\left(0.3 \mathrm{mg} \cdot \mathrm{kg}^{-1}\right.$. $\min ^{-1}$ ), after which the LAD was ligated just distal to the first diagonal branch for 75 minutes. After LAD ligation, a 2-mm diameter cannula (DLPlegia Highflow Vessel Cannulae; Medtronic DLP, Grand Rapids, Mich) was inserted into the LAD distal to the site of ligation. Ventricular fibrillation, when encountered, was converted by direct-current countershock of $10 \mathrm{~W} / \mathrm{s}$. When more than 4 countershocks were required, ventricular fibrillation was termed intractable, and the experiment was terminated. At the end of 75 minutes of LAD occlusion, all data were again collected. The LAD cannula was then attached to a delivery line from the Myocardial Protection System (MPS) cardioplegia and perfusion delivery system (Quest Medical Inc, Allen, Tex), and reperfusion was established by continuous withdrawal of femoral arterial blood. Mean LAD pressure was immediately matched to mean systemic arterial pressure by varying flow rate during the entire reperfusion period. The dogs were randomly given saline solution vehicle (vehicle group, $\mathrm{n}=7$ ) or $10 \mu \mathrm{mol} / \mathrm{L}$ blood adenosine (adenosine group, $\mathrm{n}=7$ ) at a rate of $10 \mathrm{~mL} / \mathrm{L}$ blood into the LAD during the first 30 minutes of reperfusion, followed by unmodified reperfusion for 90 minutes. Adenosine was administered through side ports situated just proximal to the heart in the perfusion line to avoid rapid deamination during transit. After reperfusion was established with the MPS system, the perfusion line was used for injection of colored microspheres and withdrawal of reference samples to determine myocardial blood flow specifically in the area at risk (AAR). Coronary blood flow rate was increased to compensate for reference sample withdrawal from the catheter. 

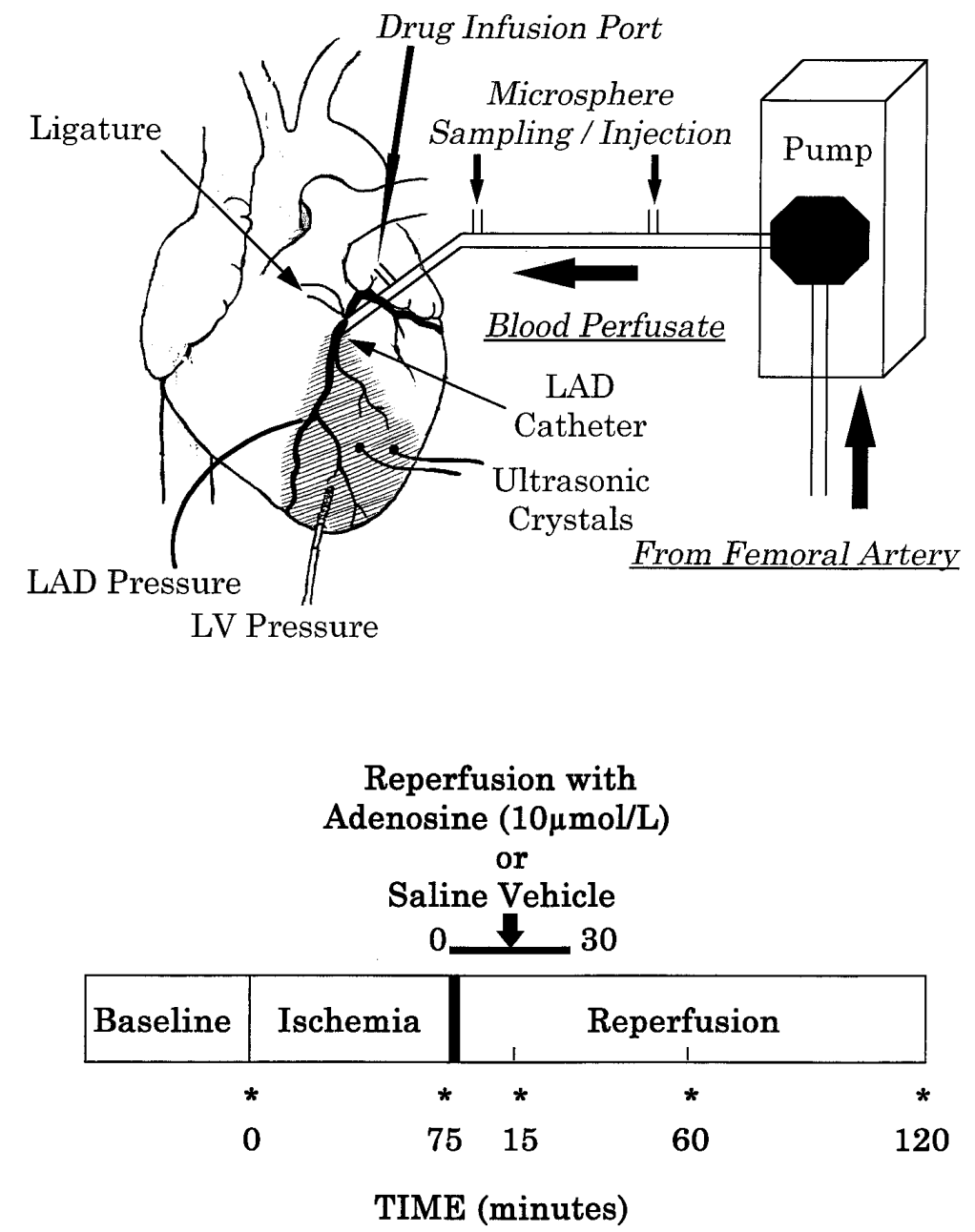

Fig 1. A, Diagram of the surgical preparation and LAD perfusion circuit. After the induction of ischemia, the LAD was cannulated distal to the occlusive ligature to perfuse the area at risk (hatched area). During the first 30 minutes of reperfusion, either adenosine or saline solution was administered by using the computerized additive circuit through the side ports situated just proximal to the LAD catheter in the perfusion line. B, Experimental protocol. Time points are indicated for injection of colored microspheres and data collection.

Data collection and analysis. Hemodynamic data, including left ventricular, systemic arterial (femoral arterial), and LAD pressures and segmental length data were acquired during the 10 -second period of respiratory apnea. The data from each channel were digitized and processed by computer algorithms by means of an interactive videographics program developed in our laboratory (SPECTRUM; Wake Forest University, Winston-Salem, NC), as described previously. ${ }^{10}$ Percentage of segmental shortening was calculated as follows:

$$
100 \times(\mathrm{EDL}-\mathrm{ESL}) / \mathrm{EDL},
$$

where EDL and ESL are end-diastolic length and end-systolic length, respectively.

Determination of AAR and infarct size. After postexperimental excision of the heart, unisperse blue dye was injected under $100 \mathrm{~mm} \mathrm{Hg}$ perfusion pressure to stain the normally perfused region blue and demarcate the AAR. The left ventricle (LV) was cut into 4- to 5-mm thick transverse slices. The AAR was separated from the nonischemic zone and incubated for 15 minutes in $1 \%$ solution of triphenyltetrazolium chloride (Sigma Chemical, St Louis, Mo) at $37^{\circ} \mathrm{C}$ to differentiate the necrotic zone (pale) from the ischemic nonnecrotic zone (red). The AAR was calculated as the sum of the weights of the nonnecrotic and necrotic tissue within the AAR divided by the weight of the LV and expressed as a percentage (AAR/LV). The infarct size was calculated as the weight of necrotic tissue divided by the weight of the AAR (An/AAR) and expressed as a percentage.

Regional myocardial blood flow. Regional myocardial blood flow (RMBF) with 1 to 2 million $15-\mu \mathrm{m}$ color-labeled microspheres (Triton Technology, San Diego, Calif) was cal- 
culated by the reference sampling method, as previously described. ${ }^{11}$ Reference samples were withdrawn from the femoral artery or the perfusion line at a constant rate for 3 minutes. Postexperimental myocardial tissue and reference blood samples were analyzed with a spectrophotometer (DU7400; Beckman, Fullerton, Calif). Blood flow was calculated in the nonischemic epicardium, nonischemic endocardium, AAR epicardium, and the AAR endocardium, respectively, as follows:

$$
\mathrm{RMBF}=\left(\mathrm{C}_{\mathrm{T}} \times \mathrm{F}_{\mathrm{R}} / \mathrm{C}_{\mathrm{R}}\right) / \mathrm{W}_{\mathrm{T}},
$$

where $C_{T}$ and $C_{R}$ are the absorbances from dispersed microspheres in the tissue and reference blood samples, respectively; $F_{R}$ is the reference flow rate; and $\mathrm{W}_{\mathrm{T}}$ is the total weight of the tissue sample in grams. Results are expressed as milliliters per minute per gram of tissue.

Plasma creatine kinase activity. Arterial blood samples $(3 \mathrm{~mL})$ were centrifuged at $2500 \mathrm{~g}$ and $4^{\circ} \mathrm{C}$ for 10 minutes. The plasma was drawn off and analyzed spectrophotometrically for creatine kinase (CK) activity and for protein concentration (CK-10 kit; Sigma Diagnostics, St Louis, Mo). Plasma CK activity is expressed as international units per gram of protein.

Determination of myocardial edema. Postexperimental transmural myocardial tissue samples were taken from the nonischemic zone and from the AAR. Each sample was further subdivided into subepicardial and subendocardial regions, blotted of surface moisture, weighed, and desiccated for 48 hours. The percentage of myocardial water content is defined as follows:

$$
\text { [(wet weight }- \text { dry weight }) / \text { wet weight }] \times 100
$$

Cardiac myeloperoxidase activity. Postexperimental transmural myocardial tissue samples were taken from the nonischemic zone and from the nonnecrotic and necrotic areas of the AAR for spectrophotometric analysis of myeloperoxidase (MPO) activity as an assessment of neutrophil accumulation in myocardium, as described previously. ${ }^{12}$ MPO activity is described as the rate of hydrogen peroxide degradation-induced color change per minute per 100 $\mathrm{mg}$ of tissue and expressed as the change in absorbance units per minutes per gram of myocardial tissue.

Postexperimental coronary artery endothelial function. Both the ischemic-reperfused LAD and nonischemic circumflex coronary arteries (LCx) were carefully dissected from the heart and cut into rings of approximately $2 \mathrm{~mm}$ in length. The rings were mounted on stainless steel hooks and placed in organ chambers filled with $37^{\circ} \mathrm{C}$ Krebs-Henseleit solution oxygenated with $95 \%$ oxygen and $5 \%$ carbon dioxide, having the following composition: $\mathrm{NaCl}, 118.1$ $\mathrm{mmol} / \mathrm{L} ; \mathrm{KCl}, 4.7 \mathrm{mmol} / \mathrm{L} ; \mathrm{KH}_{2} \mathrm{PO}_{4}, 1.2 \mathrm{mmol} / \mathrm{L} ; \mathrm{MgSO}_{4}$, $1.2 \mathrm{mmol} / \mathrm{L} ; \mathrm{CaCl}_{2} \cdot 2 \mathrm{H}_{2} \mathrm{O}, 2.5 \mathrm{mmol} / \mathrm{L} ; \mathrm{NaHCO}_{3}, 25.0$ $\mathrm{mmol} / \mathrm{L}$; and glucose, $11.1 \mathrm{mmol} / \mathrm{L}$. Changes in isometric force were measured by isometric force transducers (model TR001; Radnoti, Monrovia, Calif), as described previously, ${ }^{10}$ after 60 minutes of equilibration with $10 \mu \mathrm{mol} / \mathrm{L}$ indomethacin (INN: indometacin) to prevent vascular responses to endogenous prostacyclin. The coronary rings were precontracted with the $10 \mathrm{nmol} / \mathrm{L}$ thromboxane $\mathrm{A}_{2}$ mimetic agent U46619 (Upjohn, Kalamazoo, Mich). Once a stable contraction was observed, cumulative concentration responses to acetylcholine (Sigma Chemical), a muscarinic receptor-mediated endothelium-dependent stimulator of nitric oxide synthase, were obtained. After the rings were washed with fresh Krebs-Henseleit solution and equilibrated to baseline, the procedure was repeated for A23187 (Sigma Chemical), a receptor-independent stimulator of nitric oxide synthase, and for sodium nitroprusside (Sigma Chemical) to test endothelium-independent vascular smooth muscle relaxation. Relaxation is expressed as a percentage of U46619-induced constriction. Drug concentrations are expressed as the final concentration in the organ chamber.

Statistical analysis. The data were analyzed by 1-way or 2-way analysis of variance for repeated measures to identify group, time, and group-time interactions. If significant interactions were found, then further pairwise analysis was performed by using post hoc analysis to locate the source of differences. Comparisons between the 2 groups in the AAR, infarct size, MPO activity, myocardial edema, and percentage of relaxation of coronary rings at each concentration were analyzed by the nonpaired Student $t$ test. Mean \pm SEM values are reported.

\section{Results}

Eighteen animals were initially entered into the experimental phase of the study. Four were excluded because of intractable ventricular fibrillation during 75 minutes of LAD occlusion. The remaining dogs were randomly given saline vehicle (vehicle group, $n=7$ ) or $10 \mu \mathrm{mol} / \mathrm{L}$ blood adenosine (adenosine group, $\mathrm{n}=7$ ). The data from 14 dogs of either sex weighing 22.0 to $31.8 \mathrm{~kg}$ (average weight, $27.4 \mathrm{~kg}$ ) were analyzed and presented.

Hemodynamic data and segmental function. Hemodynamic data and segmental shortening during the course of the experiment are shown in Table I. There were no significant differences between the 2 groups in any of the hemodynamic variables and segmental shortening in the AAR at baseline. Furthermore, there were no changes in mean arterial pressure during the course of the experiment in either group. Note that delivery of adenosine to the AAR did not produce hypotension (see R15 in Table I). At ischemia and 15 minutes of reperfusion, left ventricular end-diastolic pressure increased significantly in the vehicle group but subsequently returned to the baseline level, and no significant differences were found between groups. Ischemia caused paradoxical systolic expansion of the ischemic segment. During reperfusion, akinesis or dyskinesis of systolic shortening persisted in both groups, with no group differences. 
Table I. Hemodynamic data and segmental shortening data for the I-R segment

\begin{tabular}{lllcccc}
\hline Variable & Group & Baseline & Ischemia & $R 15$ & $R 60$ & $R 120$ \\
\hline HR (beats/min) & Vehicle & $86.6 \pm 11.5$ & $108.7 \pm 6.8$ & $111.5 \pm 6.6^{*}$ & $110.7 \pm 5.8^{*}$ & $126.9 \pm 7.7^{*}$ \\
& Adenosine & $69.4 \pm 4.5$ & $100.8 \pm 8.6^{*}$ & $107.1 \pm 7.0^{*}$ & $110.1 \pm 11.8^{*}$ & $116.3 \pm 8.5^{*}$ \\
LVSP (mm Hg) & Vehicle & $96.0 \pm 4.5$ & $84.2 \pm 4.4^{*}$ & $83.1 \pm 3.7^{*}$ & $81.3 \pm 5.3^{*}$ & $85.6 \pm 1.8^{*}$ \\
& Adenosine & $88.3 \pm 2.0$ & $85.6 \pm 5.9$ & $85.1 \pm 5.6$ & $86.0 \pm 6.3$ & $82.9 \pm 5.7$ \\
LVEDP (mm Hg) & Vehicle & $10.4 \pm 0.7$ & $14.3 \pm 0.9^{*}$ & $13.8 \pm 1.2^{*}$ & $12.2 \pm 1.1$ & $9.7 \pm 0.8$ \\
& Adenosine & $10.3 \pm 0.7$ & $14.4 \pm 2.1$ & $12.2 \pm 1.4$ & $10.7 \pm 1.8$ & $8.7 \pm 0.9$ \\
MAP (mm Hg) & Vehicle & $77.9 \pm 4.1$ & $79.3 \pm 7.8$ & $78.6 \pm 7.4$ & $74.8 \pm 8.7$ & $77.6 \pm 4.9$ \\
& Adenosine & $75.8 \pm 3.4$ & $78.9 \pm 7.6$ & $76.7 \pm 7.5$ & $76.9 \pm 6.7$ & $72.0 \pm 6.6$ \\
MLADP (mm Hg) & Vehicle & $72.9 \pm 3.7$ & $18.7 \pm 1.9^{*}$ & $72.2 \pm 1.2$ & $67.7 \pm 4.5$ & $73.5 \pm 3.5$ \\
& Adenosine & $68.1 \pm 1.6$ & $12.9 \pm 1.1^{*}$ & $69.0 \pm 5.6$ & $70.4 \pm 2.6$ & $67.3 \pm 1.2$ \\
SS\% & Vehicle & $14.3 \pm 2.6$ & $-4.6 \pm 1.4^{*}$ & $-1.9 \pm 2.1^{*}$ & $-1.8 \pm 1.5^{*}$ & $-3.1 \pm 1.9^{*}$ \\
& Adenosine & $12.7 \pm 1.1$ & $-5.0 \pm 0.8^{*}$ & $-2.4 \pm 1.4^{*}$ & $-0.8 \pm 2.4^{*}$ & $0.3 \pm 2.1^{*}$ \\
\hline
\end{tabular}

$H R$, Heart rate; $L V S P$, left ventricular systolic pressure; $L V E D P$, left ventricular end-diastolic pressure; MAP, mean arterial pressure; MLADP, mean LAD pressure; $S S \%$, percentage of segmental shortening; $R 15, R 60$, and $R 120,15,60$ and 120 minutes of reperfusion, respectively.

$* P<.05$ versus baseline.

Coronary and myocardial blood flow to the AAR. LAD blood flow measured by the MPS pump system during reperfusion is shown in Fig 2. Reperfusion was achieved by adjusting pump flow to match LAD pressure to mean arterial pressure. LAD blood flow was significantly higher in the adenosine group $(146.8 \pm 20.7 \mathrm{~mL} / \mathrm{min})$ compared with the vehicle group $(85.2 \pm 5.5 \mathrm{~mL} / \mathrm{min})$ at 2 minutes of reperfusion. Blood flow remained significantly higher in the adenosine group during the 30-minute drug delivery period. After adenosine or saline solution infusion was discontinued, blood flow promptly decreased in the adenosine group to levels comparable with those of the vehicle group (Fig 2). During the remainder of reperfusion, LAD blood flow remained comparable between the 2 groups. At the end of 2 hours of reperfusion, LAD blood flow averaged $24.0 \pm 4.0 \mathrm{~mL} / \mathrm{min}$ in the adenosine group and $24.2 \pm 5.1 \mathrm{~mL} / \mathrm{min}$ in the vehicle group.

RMBF. Results of RMBF in the subepicardial and subendocardial regions from both ischemic and nonischemic zones measured by colored microspheres are summarized in Table II. LAD occlusion caused blood flow in the ischemic subendocardium to decrease significantly by $93.4 \%$ and $91.6 \%$ of baseline in the vehicle and adenosine groups, respectively. This level of collateral blood flow in the AAR was comparable between groups. After 15 minutes of reperfusion, there was a significant reactive hyperemia in the subendocardium in both groups, with that in the adenosine group being significantly greater than that in the vehicle group. After 120 minutes of reperfusion, blood flow remained elevated in the AAR subendocardium relative to baseline values in both groups (38.6\% and $162.4 \%$ above baseline in the vehicle and adenosine groups, respectively), which tended to be greater in the adenosine group. In the AAR subepicardium similar but moderate changes in regional blood flow were observed. Blood flow to the nonischemic zone showed no significant changes in either group during the LAD occlusion.

AAR and infarct size. The AAR/LV was comparable between groups (Fig 3). The infarct size in the adenosine group, calculated either as $\mathrm{An} / \mathrm{LV}$ or An/AAR $(2.6 \% \pm 0.8 \%$ and $11.1 \% \pm 3.0 \%$, respectively), was significantly smaller than those values $(7.3 \% \pm$ $1.3 \%$ and $28.0 \% \pm 4.0 \%$, respectively) in the vehicle group (Fig 3).

Plasma CK activity. Plasma CK at baseline was comparable between the 2 groups (Fig 4, A). After 60 minutes of reperfusion, CK activity was significantly less in the adenosine group and remained less at the end of reperfusion compared with that of the vehicle group $(18.4 \pm 3.5$ vs $8.5 \pm 1.2 \mathrm{IU} / \mathrm{g}$ protein, respectively). These data are consistent with the significantly reduced infarct size observed in the adenosine group.

Myocardial edema. After 2 hours of reperfusion, the myocardium of the vehicle group demonstrated the greatest myocardial edema in the AAR subendocardium, with tissue water content averaging $85.8 \% \pm 1.2 \%$ (Fig $4, B$ ). In the adenosine group there was a significant reduction in myocardial edema in the ischemic subendocardium $(81.9 \% \pm 1.1 \%)$ compared with that in the vehicle group. Myocardial edema in the AAR subepicardium tended to be lower in the adenosine group but with no significant difference between the 2 groups. In the normal zone myocardial edema was comparable between the 2 groups. 


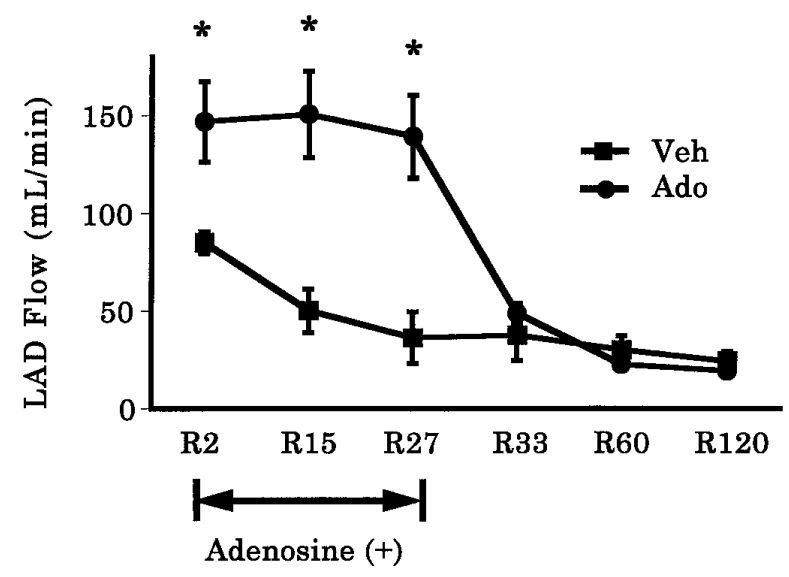

Fig 2. Mean LAD coronary artery blood flow (in milliliters per minute) delivered by the MPS pump system during the course of reperfusion. $R 2, R 15, R 27, R 33, R 60$, and $R 120,2$, $15,27,33,60$, and 120 minutes of reperfusion, respectively; $R 30 \mathrm{~b}$ and $R 30 \mathrm{a}, 3$ minutes before and after discontinuation of adenosine or saline solution, respectively. $* P<.05$ versus the vehicle group. Veh, Vehicle group; Ado, adenosine group.

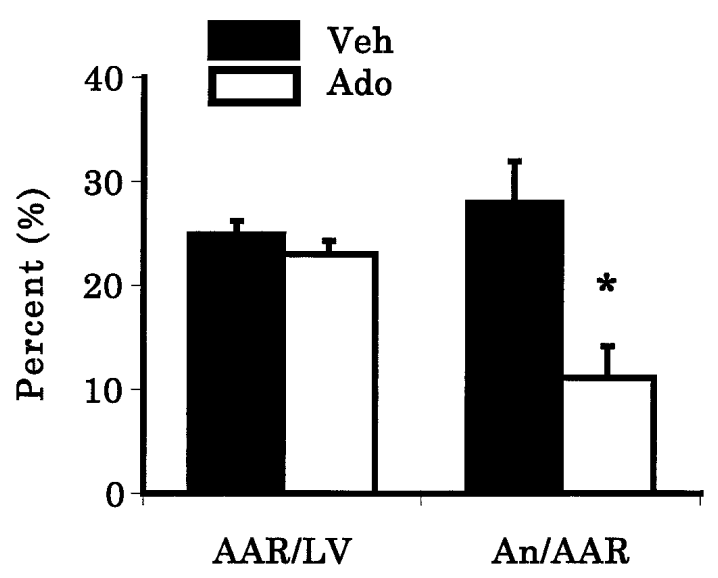

Fig 3. Size of the area at risk relative to the left ventricular mass $(A A R / L V)$ and infarct size as area of necrosis relative to area at risk $(A n / A A R) . * P<.05$ versus the vehicle group. Veh, Vehicle group; $A d o$, adenosine group.

Table II. Regional myocardial blood flow for ischemic and nonischemic zone

\begin{tabular}{|c|c|c|c|c|c|}
\hline & \multirow[b]{2}{*}{ Group } & \multicolumn{2}{|c|}{ Ischemic zone } & \multicolumn{2}{|c|}{ Nonischemic zone } \\
\hline & & Epicardium & Endocardium & Epicardium & Endocardium \\
\hline \multirow[t]{2}{*}{ Baseline } & Vehicle & $0.686 \pm 0.073$ & $0.606 \pm 0.073$ & $0.609 \pm 0.083$ & $0.816 \pm 0.106$ \\
\hline & Adenosine & $0.483 \pm 0.030$ & $0.368 \pm 0.027$ & $0.482 \pm 0.068$ & $0.518 \pm 0.059$ \\
\hline \multirow[t]{2}{*}{ Ischemia } & Vehicle & $0.072 \pm 0.035^{*}$ & $0.041 \pm 0.014^{*}$ & $0.574 \pm 0.063$ & $0.753 \pm 0.057$ \\
\hline & Adenosine & $0.065 \pm 0.020 *$ & $0.029 \pm 0.005^{*}$ & $0.523 \pm 0.090$ & $0.558 \pm 0.069$ \\
\hline \multirow[t]{2}{*}{ R15 } & Vehicle & $1.132 \pm 0.133^{*}$ & $1.143 \pm 0.140^{*}$ & - & - \\
\hline & Adenosine & $1.429 \pm 0.250 *$ & $1.550 \pm 0.275^{*}$ & - & - \\
\hline \multirow[t]{2}{*}{ R60 } & Vehicle & $0.916 \pm 0.090 *$ & $0.943 \pm 0.107 *$ & - & - \\
\hline & Adenosine & $1.015 \pm 0.330$ & $1.164 \pm 0.320^{*}$ & - & - \\
\hline \multirow[t]{2}{*}{ R120 } & Vehicle & $0.795 \pm 0.108$ & $0.794 \pm 0.116$ & - & - \\
\hline & Adenosine & $0.856 \pm 0.265$ & $0.973 \pm 0.255^{*}$ & - & - \\
\hline
\end{tabular}

Values are expressed as milliliters per minute per gram of tissue. Blood flow in the nonischemic zone is absent because of local delivery of microspheres to the area at risk through the perfusion cannula. $R 15, R 60$, and $R 120,15,60$, and 120 minutes of reperfusion, respectively.

$* P<.05$ versus baseline.

Cardiac MPO activity. MPO activity in the nonischemic zone was low and comparable between the 2 groups (Fig 5). In the triphenyltetrazolium chloridenegative necrotic tissue within the AAR, MPO activity was $36 \%$ less in the adenosine group than in the vehicle group, although there was no statistical difference. MPO activity in the AAR nonnecrotic tissue was comparable between the 2 groups.

Postischemic coronary artery endothelial function. Vasodilator responses to acetylcholine, A23187, and sodium nitroprusside in isolated coronary artery rings taken from the ischemic-reperfused LAD and the nonis- chemic LCx are summarized in Fig 6. Fig 6, $A$, shows the percentage of relaxation with vasodilators in the ischemic-reperfused LAD rings. The response to acetylcholine, an endothelium-dependent and muscarinic receptor-mediated vasodilator, was significantly greater in the adenosine group (maximum, $97.9 \% \pm 5.6 \%$ relaxation with the highest concentration) compared with that in the vehicle group (maximum, 64.7\% $\pm 6.5 \%$ ). Furthermore, endothelium-dependent nonreceptor-mediated vasodilation to A23187 was associated with significantly greater relaxation in the adenosine group (maximum, $84.6 \% \pm 3.5 \%$ ) than in the vehicle group 

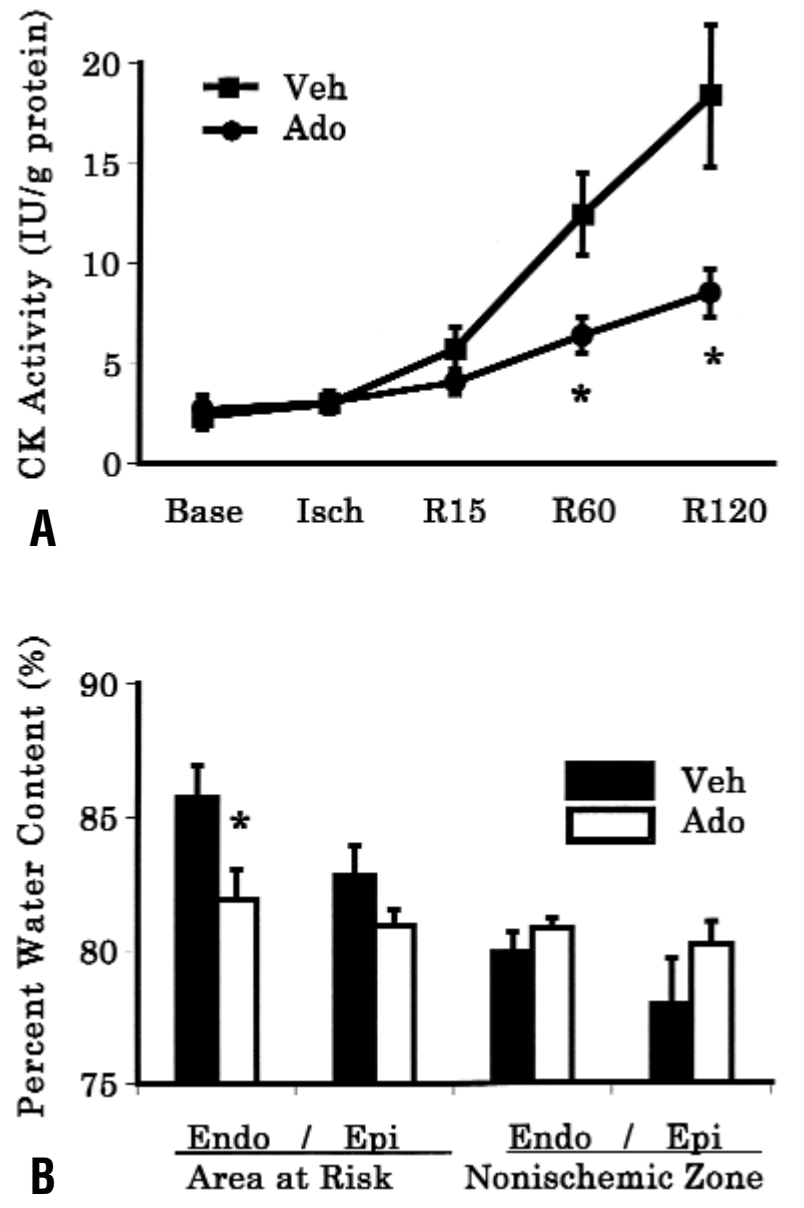

Fig 4. A, Plasma CK activity during the time course of the experiment. Base, Baseline; Isch, ischemia; R15, R60, and $R 120,15,60$, and 120 minutes of reperfusion, respectively. $* P<.05$ versus the vehicle group. B, Myocardial water content after desiccation of subendocardial (Endo) and subepicardial (Epi) tissue samples in both area at risk and nonischemic zone at the end of the experiment. $* P<.05$ versus the vehicle group. Veh, Vehicle group; Ado, adenosine group.

(maximum, 58.7\% $\pm 7.8 \%$ ). The endothelium-independent vasodilator sodium nitroprusside resulted in complete relaxation in both groups, with no significant group difference. These data indicate that modified reperfusion with adenosine protects endothelial function from I-R injury, whereas vascular smooth muscle function remains intact. Coronary rings taken from nonischemic LCx (Fig $6, B$ ) relaxed comparably by all 3 vasodilators with no group differences at any concentration.

\section{Discussion}

Although beating heart coronary artery bypass graft operations have recently gained popularity, ${ }^{13,14}$ the technique limits the application of cardioprotective

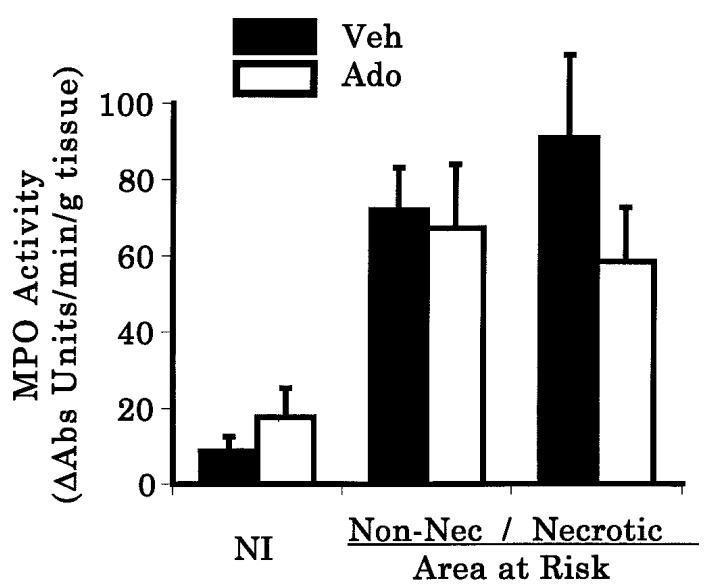

Fig 5. MPO activity in nonischemic (NI), nonnecrotic (Non$\mathrm{Nec}$ ), and necrotic area at risk of myocardial tissue samples from each group. Veh, Vehicle group; Ado, adenosine group.

strategies that have been extensively investigated over the past 20 years (ie, cardioplegia and hypothermia). During OPCABG, reperfusion after a period of coronary artery occlusion is established without any active cardioprotection. For the moment, strategies such as proximal first technique or the use of intraluminal coronary shunts have been applied to minimizing the effects of ischemia during elective coronary occlusion, especially in multivessel OPCABG. ${ }^{15,16}$ Measures such as ischemic preconditioning of target vascular beds have also been advocated, but its effects are not clear, and clinical efficacy for regional ischemia is not known. ${ }^{17,18}$ In this regard the novel PADCAB technique for off-pump operations allows not only rapid reperfusion but also the delivery of cardioprotective agents directly into the ischemic-reperfused target area. ${ }^{3}$ The PADCAB technique of coronary perfusion was originally applied to graft conduits after the completion of the distal anastomosis. However, with the aid of an intraluminal device, the target coronary artery can be perfused directly, thereby avoiding ischemia induced by vascular snares. This intraluminal perfusion closely simulates the experimental conditions used in the present study.

In the present study the myocardium at risk underwent 75 minutes of ischemia at the time of reperfusion. This duration of ischemia simulates acute myocardial infarction rather than routine OPCABG revascularization in an elective procedure. However, even during OPCABG operations, a relatively long ischemic period may be required, and full perfusion of the target area may not be achieved until the proximal anastomosis is completed, thereby involving a longer duration of com- 


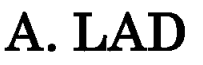

\section{B. LCx}
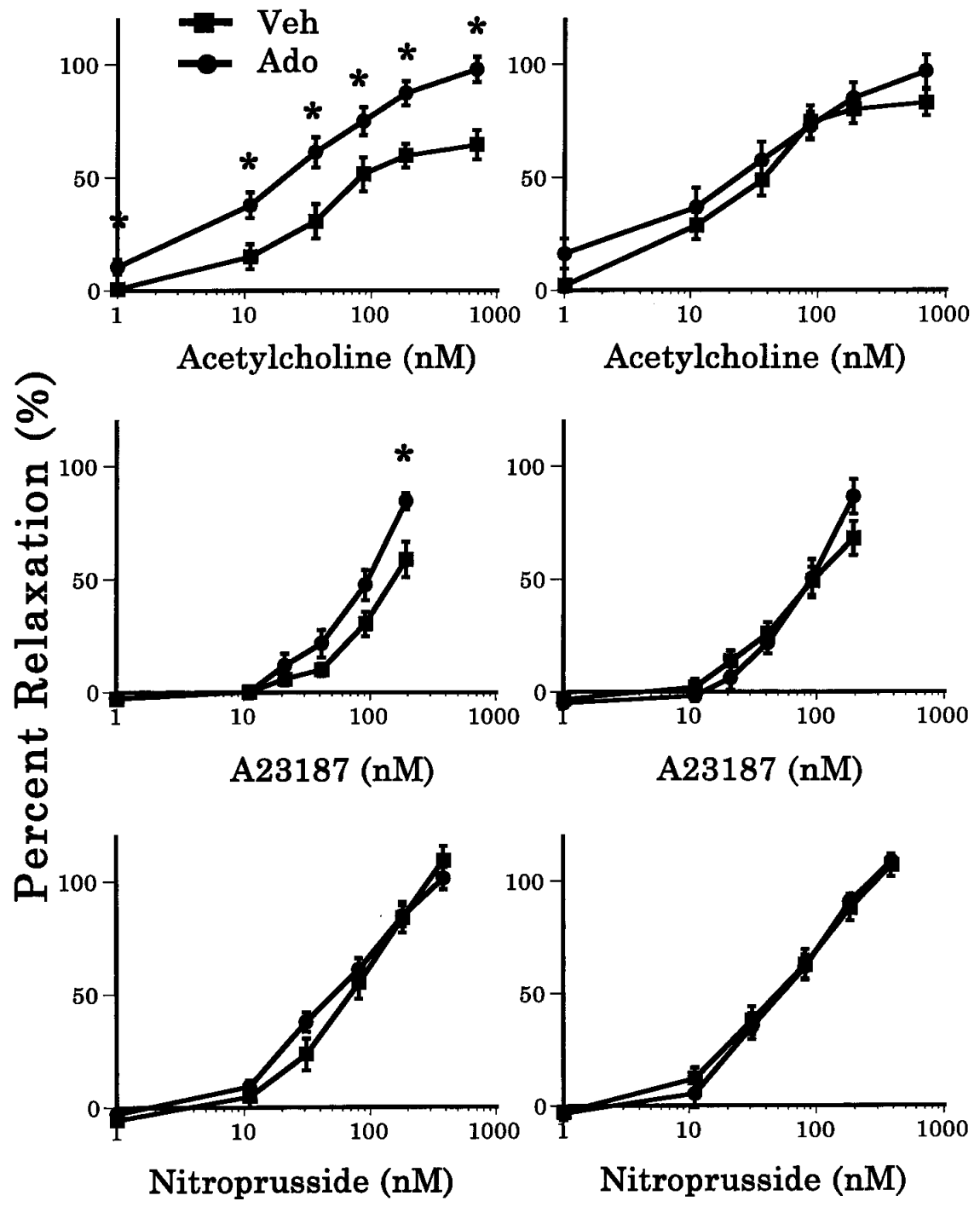

A23187 (nM)

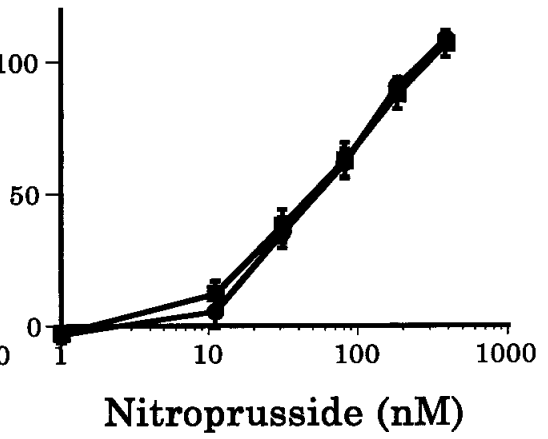

Fig 6. Vasodilator response to acetylcholine, A23187, and sodium nitroprusside in ischemic-reperfused LAD (A) and nonischemic LCx rings $(\mathbf{B}) .{ }^{*} P<.05$ versus the vehicle group.Veh, Vehicle group; Ado, Adenosine group.

promised blood supply. In a patient with a low-grade stenosis, the ischemia may not extend beyond removal of the ligature. However, the presence of a severe stenosis may impair adequate blood flow until the proximal anastomosis is completed. Additionally, even the short ischemic period (usually $<15$ minutes) necessary for routine OPCABG may produce subtle injury (metabolic disarrangement or reversible myocardial dysfunction), ${ }^{19,20}$ although it may not produce severe injury. In any event the indications for OPCABG may extend to patients with acute myocardial infarctions in the future, for which strategies to attenuate I-R injury will be important for postoperative cardiac function and improvement of mortality.

Intracoronary administration of adenosine (10 $\mu \mathrm{mol} / \mathrm{L}$ ) during the first 30 minutes of reperfusion, as an additive to the blood perfusing the ischemic myocardial segment, reduced infarct size by $60 \%$ of that observed in the saline vehicle group. This reduction in infarct size was consistent with previous studies ${ }^{8,21}$ and was associated with a significant decrease in plasma CK activity and myocardial edema. The reduction in myocardial edema is likely related to preservation of the microvascular endothelium, consistent with our 
data in epicardial vessels. In addition, brief adenosine treatment significantly attenuated endothelial injury and tended to reduce the accumulation of neutrophils in the necrotic AAR. Moreover, the selective intracoronary administration of adenosine did not alter systemic blood pressure. Hence, transient intracoronary adenosine could be safely delivered to the target vessel myocardium to attenuate reperfusion injury, although this reduction of I-R injury was not associated with recovery of postischemic segmental function at the end of 2 hours of reperfusion.

Previous studies have demonstrated the potent cardioprotective effects of adenosine, including direct inhibition of neutrophils (superoxide anion generation and expression of adhesion molecules) and inhibition of endothelial activation, which attenuated neutrophilendothelial interactions. ${ }^{21-23}$ These effects are largely mediated by $\mathrm{A}_{2 \mathrm{a}}$ receptor interactions, ${ }^{5,24}$ although interaction with the newly identified $\mathrm{A}_{3}$ receptor has been reported to attenuate neutrophil adherence to endothelium. ${ }^{9,25}$ These mechanisms, rather than increased blood flow, have been suggested to play major roles in the reduction of infarction after myocardial ischemia and subsequent reperfusion when adenosine was administered at reperfusion. ${ }^{21}$

The strategy of administering exogenous adenosine to reduce reperfusion injury has been described recently, ${ }^{6,21,26,27}$ and numerous studies have demonstrated that adenosine can restore various biochemical alterations with or without functional recovery. ${ }^{5,28,29}$ Consistent with previous studies in which adenosine was administered by intracoronary infusion, ${ }^{6,30,31}$ the present study demonstrated a reduction of infarct size and preservation of endothelial function, although postischemic segmental function showed no recovery, presumably because of our relatively short reperfusion duration. As another possible reason, it has been demonstrated that neutrophils are not involved in the pathogenesis of regional contractile dysfunction, ${ }^{32}$ although this is still controversial. Therefore, inhibition of neutrophil actions with adenosine may not be associated with improvement of regional segmental function in infarct models. Considering the short half-life $(<15$ seconds) of adenosine in whole blood, ${ }^{33}$ the most effective method of adenosine administration is likely to be selective intracoronary treatment introduced into the blood just proximal to the coronary catheter.

In the present study $10 \mu \mathrm{mol} / \mathrm{L}$ adenosine was infused directly into the LAD during the first $30 \mathrm{~min}$ utes for a total volume of 40 to $60 \mathrm{~mL}(10-15 \mathrm{mg}$ adenosine). Although the concentration is fairly low and the infusion period is short compared with that found in previous studies, ${ }^{6,30,31}$ the findings from our study suggest that our delivery method of adenosine is effective in salvaging myocardium and attenuating endothelial injury in the PADCAB setting without hypotension. The short infusion period is clinically relevant, especially when PADCAB is used for multiple grafts, although it is not known whether $30 \mathrm{~min}$ utes of intracoronary adenosine is optimal. In addition, the delivery of adenosine can be precisely controlled by the computerized pump system with an accuracy of $\pm 1 \%$ over a wide range of flow rates. ${ }^{34} \mathrm{In}$ the present study coronary perfusion pressure was matched to systemic arterial pressure by varying flow rate during the entire reperfusion period. It is important that coronary pressure is measured directly with an intraluminal catheter or estimated from transcatheter pressure differentials because several previous studies have demonstrated that there is a safe limit of pressure for the vulnerable myocardium at the time of reperfusion, beyond which myocardial damage (interstitial edema) is observed. ${ }^{35}$ In this regard the perfusion pressure used in our study was comparable with that of passive flow systems, although the pump flow was not pulsatile.

In summary, the present study determined that intracoronary perfusion of at-risk myocardium with adenosine during the first 30 minutes of reperfusion reduced the extent of myocardial infarction in a simulated PAD$\mathrm{CAB}$ model. In addition, endothelial function was highly preserved with adenosine treatment. This novel reperfusion strategy for OPCABG can be used in cases requiring single, as well as multiple, grafting and prolonged ischemia and for patients with acute evolving myocardial infarction.

We thank Rachel Otto, Jill Robinson, Sara Katzmark, and L. Susan Schmarkey for their technical assistance and Gail Nechtman for word processing.

Received for publication July 28, 2000; revisions requested Sept 7, 2000; revisions received Sept 27, 2000; accepted for publication Sept 29, 2000.

Address for reprints: Jakob Vinten-Johansen, MD, Cardiothoracic Research Laboratory, 550 Peachtree St, NE, Atlanta, GA 30365-2225 (E-mail: jvinten@emory.edu).

\section{REFERENCES}

1. Ambrosio G. Reperfusion injury: experimental evidence and clinical implications. Am Heart J 1999;138:S69-75.

2. Boyle EM Jr, Pohlman TH, Cornejo CJ, Verrier ED. Ischemiareperfusion injury. Ann Thorac Surg 1996;64:S24-30.

3. Guyton RA, Thourani VH, Puskas JD, Shanewise JS, Steele MA, Palmer-Steele CL, et al. Perfusion-assisted direct coronary artery bypass: selective graft perfusion in off-pump cases. Ann Thorac Surg 2000;69:171-5. 
4. Mentzer RM Jr, Birjiniuk V, Khuri S, Lowe JE, Rahko PS, Weisel $\mathrm{RD}$, et al. Adenosine myocardial protection: preliminary results of a phase II clinical trial. Ann Surg 1999;229:643-50.

5. Vinten-Johansen J, Thourani VH, Ronson RS, Jordan JE, Zhao ZQ, Nakamura M, et al. Broad-spectrum cardioprotection with adenosine. Ann Thorac Surg 1999;68:1942-8.

6. Babbitt DG, Virmani R, Forman MB. Intracoronary adenosine administered after reperfusion limits vascular injury after prolonged ischemia in the canine model. Circulation 1989;80:1388-99.

7. Lasley RD, Rhee JW, Van Wylen DGL, Mentzer RM Jr. Adenosine $A_{1}$ receptor mediated protection of the globally ischemic isolated rat heart. J Mol Cell Cardiol 1990;22:39-47.

8. Jordan JE, Zhao ZQ, Sato H, Taft S, Vinten-Johansen J. Adenosine $\mathrm{A}_{2}$ receptor activation attenuates reperfusion injury by inhibiting neutrophil accumulation, superoxide generation and coronary endothelial adherence. J Pharmacol Exp Ther 1997;280:301-9.

9. Jordan JE, Thourani VH, Auchampach JA, Robinson JA, Wang NP, Vinten-Johansen J. $A_{3}$ adenosine receptor activation attenuates neutrophil function and neutrophil-mediated reperfusion injury. Am J Physiol 1999;277:H1895-905.

10. Nakanishi K, Vinten-Johansen J, Lefer DJ, Zhao Z, Fowler WCd, McGee DS, et al. Intracoronary L-arginine during reperfusion improves endothelial function and reduces infarct size. Am J Physiol 1992;263:H1650-8.

11. Kowallic P, Schulz R, Guth BD. Measurement of regional myocardial blood flow with multiple colored microspheres. Circ Res 1991;83:974-82.

12. Zhao ZQ, Todd JC, Sato H, Ma XL, Vinten-Johansen J. Adenosine inhibition of neutrophil damage during reperfusion does not involve KATp-channel activation. Am J Physiol 1997;273:H1677-87.

13. Arom KY, Flavin TF, Emery RW, Kshettry VR, Janey PA, Petersen RJ. Safety and efficacy of off-pump coronary artery bypass grafting. Ann Thorac Surg 2000;69:704-10.

14. Tasdemir O, Vural KM, Karagoz H, Bayazit K. Coronary artery bypass grafting on the beating heart without the use of extracorporeal circulation: review of 2052 cases. J Thorac Cardiovasc Surg 1998;116:68-73.

15. van Aarnhem EE, Nierich AP, Jansen EW. When and how to shunt the coronary circulation in off-pump coronary artery bypass grafting. Eur J Cardiothorac Surg 1999;16:S2-6.

16. Dapunt OE, Raji MR, Jeschkeit S, Dhein S, Kuhn-Regnier F, Sudkamp M, et al. Intracoronary shunt insertion prevents myocardial stunning in a juvenile porcine MIDCAB model absent of coronary artery disease. Eur J Cardiothorac Surg 1999;15:173-8.

17. Flameng WJ. Role of myocardial protection for coronary artery bypass grafting on the beating heart. Ann Thorac Surg 1997;63:S18-22.

18. Bonatti J, Hangler H, Hormann C, Mair J, Falkensammer J, Mair P. Myocardial damage after minimally invasive coronary artery bypass grafting on the beating heart. Ann Thorac Surg 1998;66:1093-6.

19. Brown PM Jr, Kim VB, Boyer BJ, Lust RM, Chitwood WR Jr, Elbeery JR. Regional left ventricular systolic function in humans during off-pump coronary bypass surgery. Circulation 1999;100(Suppl):II-125-7.
20. Lockowandt U, Owall A, Franco-Cereceda A. Myocardial outflow of prostacyclin in relation to metabolic stress during offpump coronary artery bypass grafting. Ann Thorac Surg 2000;70:206-11.

21. Zhao ZQ, Nakamura M, Wang NP, Wilcox JN, Shearer S, Guyton $\mathrm{RA}$, et al. Administration of adenosine during reperfusion reduces injury of vascular endothelium and death of myocytes. Coron Artery Dis 1999;10:617-28.

22. Cronstein BN, Levin RI, Belanoff J, Weissmann G, Hirschhorn R. Adenosine: an endogenous inhibitor of neutrophil-mediated injury to endothelial cells. J Clin Invest 1986;78:760-70.

23. Zhao ZQ, Sato H, Williams MW, Fernandez AZ, VintenJohansen J. Adenosine $\mathrm{A}_{2}$-receptor activation inhibits neutrophil-mediated injury to coronary endothelium. Am J Physiol 1996;271:H1456-64.

24. Cargnoni A, Ceconi C, Boraso A, Bernocchi P, Monopoli A, Curello $S$, et al. Role of $A_{2 A}$ receptor in the modulation of myocardial reperfusion damage. J Cardiovasc Pharmacol 1999;33:883-93.

25. Tracey WR, Magee W, Masamune H, Kennedy SP, Knight DR, Buchholz RA, et al. Selective adenosine $\mathrm{A}_{3}$ receptor stimulation reduces ischemic myocardial injury in the rabbit heart. Cardiovasc Res 1997;33:410-5.

26. Mentzer RM Jr, Rahko PS, Molina-Viamonte V, Canver CC, Chopra PS, Love RB, et al. Safety, tolerance, and efficacy of adenosine as an additive to blood cardioplegia in humans during coronary artery bypass surgery. Am J Cardiol 1997;79:38-43.

27. Todd J, Zhao Z-Q, Williams MW, Sato H, Van Wylen DGL, Vinten-Johansen J. Intravascular adenosine at reperfusion reduces infarct size and neutrophil adherence. Ann Thorac Surg 1996;62:1364-72.

28. Angello DA, Headrick JP, Coddington NM, Berne RM. Adenosine antagonism decreases metabolic but not functional recovery from ischemia. Am J Physiol 1991;260:H193-200.

29. Nichols WW, Nicolini FA, Yang BC, Henson K, Stechmiller JK, Mehta JL. Adenosine protects against attenuation of flow reserve and myocardial function after coronary occlusion and reperfusion. Am Heart J 1994;127:1201-11.

30. Homeister JW, Hoff PT, Fletcher DD, Lucchesi BR. Combined adenosine and lidocaine administration limits myocardial reperfusion injury. Circulation 1990;82:595-608.

31. Velasco CE, Turner M, Cobb MA, Virmani R, Forman MB. Myocardial reperfusion injury in the canine model after $40 \mathrm{~min}$ utes of ischemia: effect of intracoronary adenosine. Am Heart $\mathrm{J}$ 1991;122:1561-70.

32. Juneau CF, Ito BR, del Balzo U, Engler RL. Severe neutrophil depletion by leucocyte filters or cytotoxic drug does not improve recovery of contractile function in stunned porcine myocardium. Cardiovasc Res 1993;27:720-7.

33. Dawicki DD, Agarwal KC, Parks RE Jr. Adenosine metabolism in whole blood: effect of nucleoside transport inhibitors and phosphate concentration. Biochem Pharmacol 1988;37:621-6.

34. Sydzyik RT, Stammers AH, Zavadil DP, Deptula JJ, Christensen KA. Evaluation of a new generation cardioplegia administration system. J Extracorporeal Technol 1997;29:145-53.

35. Johnson RE, Dorsey LM, Moye SJ, Hatcher CR Jr, Guyton RA. Cardioplegic infusion. The safe limits of pressure and temperature. J Thorac Cardiovasc Surg 1982;83:813-23. 